\title{
Smart Aggregate-Piezoceramic Patch Combination for Health Monitoring of Concrete Structures
}

\author{
Jinlei Zhao,, ${ }^{1,2}$ Tengfei Bao,, ${ }^{1,2}$ Shanying Chen, ${ }^{3}$ and Tribikram Kundu ${ }^{4}$ \\ ${ }^{1}$ State Key Laboratory of Hydrology-Water Resources and Hydraulic Engineering, Hohai University, Nanjing 210098, China \\ ${ }^{2}$ College of Water Conservancy and Hydropower, Hohai University, Nanjing 210098, China \\ ${ }^{3}$ Guiyang Aluminium Magnesium Design \& Research Institute Co., Ltd., Guiyang 550000, China \\ ${ }^{4}$ Department of Civil Engineering and Engineering Mechanics, University of Arizona, Tucson, AZ 85721, USA
}

Correspondence should be addressed to Tengfei Bao; baotf@hhu.edu.cn

Received 8 July 2015; Revised 20 November 2015; Accepted 24 November 2015

Academic Editor: Christos Riziotis

Copyright (c) 2016 Jinlei Zhao et al. This is an open access article distributed under the Creative Commons Attribution License, which permits unrestricted use, distribution, and reproduction in any medium, provided the original work is properly cited.

\begin{abstract}
A new method combining an embedded smart aggregate and surface mounted piezoceramic patches is introduced for health monitoring of concrete structures. The smart aggregate is embedded in a concrete beam as an actuator (or transmitter), and piezoceramic patches are attached on the surface of the concrete beam as sensors. Two tests using the smart aggregate and the piezoceramic patches are conducted. The first test investigates the sensitivity of the recorded signal amplitude-frequency relation on the piezoceramic patches. To explain the significant amplitude fluctuations in the results, the possibility of resonance occurring in the piezoceramic patches in a certain frequency range is verified through finite element modeling. In the second test, a damage index is proposed to evaluate the health of concrete structures and a three-point bending test is conducted to induce damage in the concrete beam. It is observed that, with increasing severity of damage in the concrete beam, the recorded signal amplitude at the patches decreases gradually while the value of the damage index increases significantly. The experimental results show that the proposed method is an effective tool for health monitoring of concrete structures.
\end{abstract}

\section{Introduction}

Concrete is the most popular man-made material in civil engineering. Many important civil infrastructures, such as bridges, dams, and tunnels, are made of concrete. Concrete structures have a long service life compared to structures made of other artificial materials. However, sometimes this material does not perform well because of the brittle nature of concrete. Since concrete is weak in tension, brittle failure of concrete under tension can occur. Therefore, it is important to ensure the safe operation of concrete structures throughout their operation life.

Damage detection and continuous health assessment are necessary for critical concrete structures. In recent years, guided wave (GW) based testing techniques have been found to be very efficient for damage detection and health assessment of various structures. Raghavan and Cesnik [1] reviewed the state of the art of the GW based structural health monitoring (SHM). In their paper, they presented the methodology of GWs in SHM and the development of GWs in various fields. Na et al. [2], Wang et al. [3], and Miller et al. [4] used GW methods for detecting the interface damage between steel bar and concrete and for corrosion monitoring in reinforced concrete. Rose $[5,6]$ provided the inspection potential of ultrasonic GWs for rail inspection. $\mathrm{Na}$ et al. $[7,8]$ demonstrated the feasibility of GWs for both underwater inspection of concrete-filled steel pipes and glass fiber reinforced polymer/concrete interface testing. Lanza di Scalea et al. [9] applied GW methods for stress monitoring and defect detection in steel strands. Kundu et al. [10] studied the propagation characteristics of GWs in corrugated plates. Test results showed that elastic waves can propagate through the corrugated plates for certain frequencies and are arrested at other frequencies. Ahmad et al. [11] demonstrated the efficiency of GWs for damage detection in buried pipes.

A critical element of GW based methods is the wave generating transducers. Piezoelectric (PZT-Lead Zirconate Titanate) material is the most commonly used material 


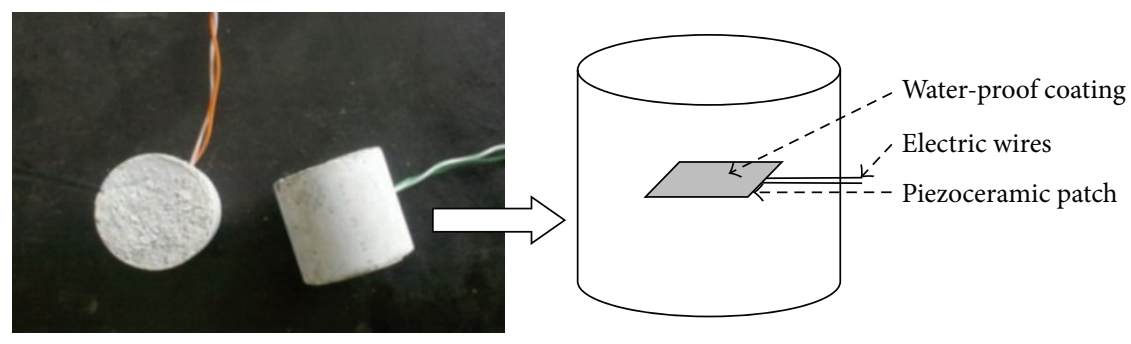

FIGURE 1: Smart aggregate.

for ultrasonic transducers. The PZT material can generate ultrasonic waves when an electric voltage is applied to it. It can also convert mechanical stress to electrical voltage when it is struck by ultrasonic waves. Due to this special property, PZT materials can be used to fabricate both actuator (or transmitter) and sensor (or receiver).

The "smart aggregate," a piezoceramic-based element, is an innovative multifunctional device. The smart aggregate has been successfully applied to the SHM of concrete structures under both static loading $[12,13]$ and seismic excitations $[14,15]$. In those studies, a number of smart aggregates were embedded in concrete structures and the health state of the concrete structures was evaluated by monitoring the signals recorded by the smart aggregates.

Most tests with smart aggregates are conducted by preembedding these piezoelectric-based elements inside the concrete structures. The combination of smart aggregates and piezoceramic patches for SHM of concrete structures has been seldom studied and will be the focus of this paper. A smart aggregate is embedded in a concrete beam to act as an actuator (or transmitter) and piezoceramic patches are attached to the surface of the concrete beam to act as sensors. The efficiency of this combination of the smart aggregate and piezoceramic patches for SHM of concrete structures is investigated here.

The elastic wave generated by the smart aggregate can propagate a long distance along the beam as the guided wave for which the beam serves as the waveguide. This guided wave can be sensed by the piezoceramic patches mounted on the beam surface. The advantage of this combination is that since the smart aggregate is embedded in concrete it is well protected from the deterioration due to the environmental effect while the smart patches can be attached at various locations of the surface of the structure to monitor different segments of the structure by recording the wave signals coming from the smart aggregate. These patches are expected to monitor not only the surface damage near the patch but also internal damage. It is shown in this investigation that it is possible to do it.

\section{Experimental Setup}

The smart aggregate was first fabricated and its schematic is shown in Figure 1. It is formed by embedding a piezoceramic patch $(10 \mathrm{~mm} \times 10 \mathrm{~mm} \times 1 \mathrm{~mm})$ with water-proof coating and lead wires into a small concrete block. The size of the small concrete block is $40 \mathrm{~mm} \times 25 \mathrm{~mm}$ (diameter $\times$ height). To reduce the reflection of signals from the back surface of the smart aggregate, an acoustic damper material layer was applied on the back side of the piezoelectric patch, as shown in Figure 2(d). The acoustic damper material was made of resins and sawdust with a weight ratio of $1: 2$ and it was $5 \mathrm{~mm}$ thick. Photographs of different stages of the fabrication process are shown in Figure 2.

The dimension of the concrete beam was $150 \mathrm{~mm} \times$ $150 \mathrm{~mm} \times 550 \mathrm{~mm}$. The beam was fabricated with $32.5 \mathrm{MPa}$ strength concrete. The water-cement-sand-aggregate weight ratio of the concrete mix was $0.44: 1: 1.42: 3.17$. To avoid brittle failure of the concrete beam during the three-point bending test, four longitudinal steel bars of $10 \mathrm{~mm}$ diameter were placed near the four corners during the fabrication process of the beam. Before pouring concrete, the smart aggregate and reinforcing bars were tied together as shown in Figure 3 and then placed in the mould. The three-point bending test was conducted using a universal testing machine.

The real-time data acquisition system consists of an arbitrary function generator or waveform signal generator (Agilent 33250A), an oscilloscope (Agilent DSO7034B), and a digital filter, as shown in Figure 4(a). BNC wires were used to connect the smart aggregate and the data recorder. The BNC wire was made of the main signal wire and a shielded wire, as shown in Figure 4(b).

\section{Testing Procedure}

During the test, sinusoidal signals with $8 \mathrm{~V} \mathrm{pp}$ (peak-to-peak) amplitude were used for frequencies varying from $100 \mathrm{~Hz}$ to $1 \mathrm{MHz}$. The smart aggregate working as the transmitter was excited by the sinusoidal signals. Piezoceramic patches were used as the receiver. Two sets of tests were conducted: first, two piezoceramic patches (PZT-S1 and PZT-S2) were attached to the surface of the concrete beam as shown in Figure 5. The received signals were detected by the two piezoceramic patches. Then, the three-point bending test was conducted on the concrete beam and the amplitudes of the received signal detected by a piezoceramic patch (PZT-S1) were recorded. A loading rate of $1.2 \mathrm{~mm} / \mathrm{min}$ was used for the three-point bending test and the concrete beam was gradually damaged during the test. The aim of these two tests is to study the influence of the excitation signals on the guided wave detected by the piezoceramic patches and to study the efficiency of this technique for SHM of concrete structures. 


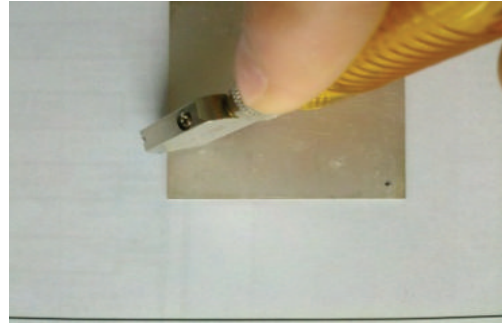

(a) Cutting

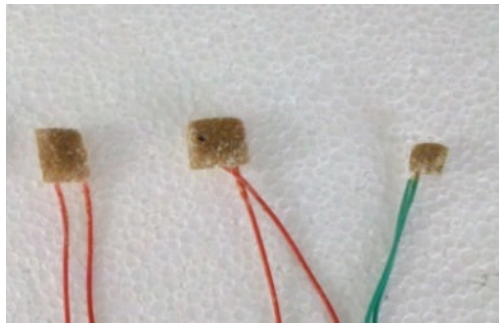

(d) Deadening treatment

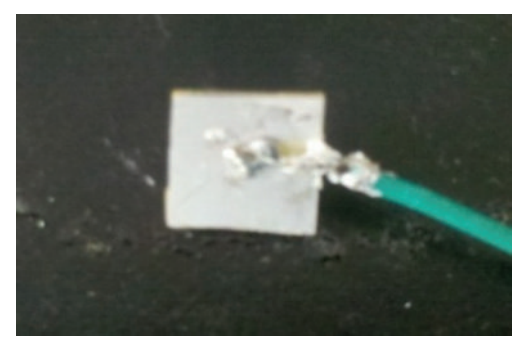

(b) Soldering

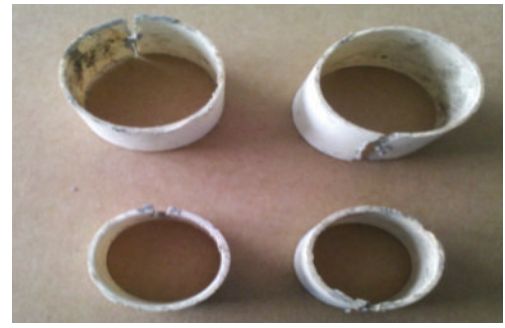

(e) Mould

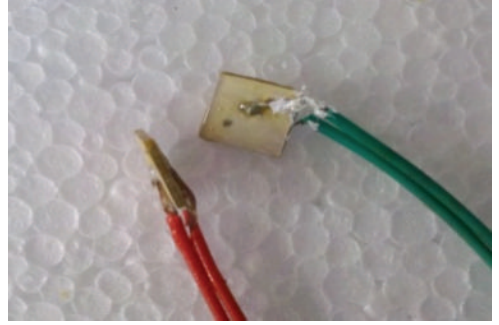

(c) Smearing resin

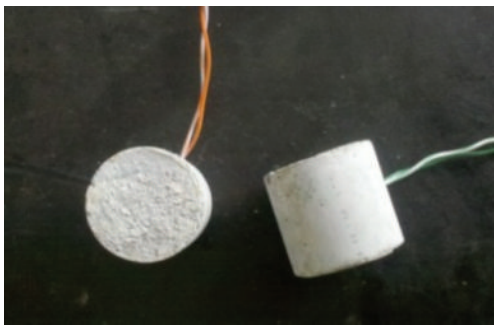

(f) Fabricated smart aggregates

FIGURE 2: Various steps of the fabrication process of smart aggregates.

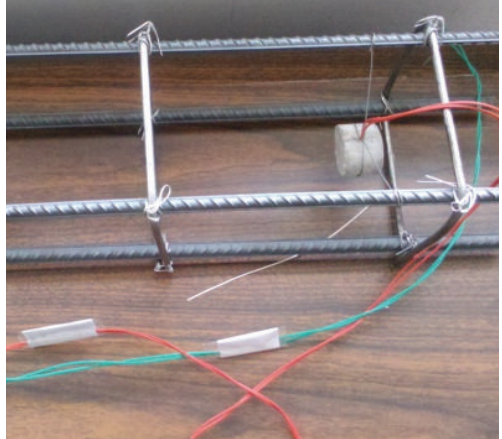

FIGURE 3: Smart aggregate and reinforcing bars that were placed in the mould.

\section{The Proposed Health Monitoring Approach}

A damage index is introduced to analyse the signals detected by the piezoceramic patches. The damage index is defined as

$$
\mathrm{DI}=\frac{\sum_{i=1}^{n} q_{i}\left|A_{h}(i)-A(i)\right|}{\sum_{i=1}^{n} q_{i} A_{h}(i)},
$$

where $i$ is the index, $A_{h}(i)$ is the amplitude of the received signal in healthy state, and $A(i)$ is the amplitude of the received signal at damage state in frequency domain. The damage index defined by comparing the transfer function in damage state with that in healthy state was used in $\mathrm{Gu}$ et al.s study [14]. A coefficient or weight factor $q_{i}$ is introduced here to the damage index to assign equal weights to all data points. $q_{i}$ is defined as

$$
\begin{gathered}
\sum_{i=1}^{n} q_{i}=1 \\
q_{i-1} A_{h}(i-1)=q_{i} A_{h}(i) .
\end{gathered}
$$

When the damage index (DI) is close to 0 , the concrete structure is healthy. Like all other DI definitions, this DI value also increases with the degree of damage: therefore, larger DI value implies more severe damage.

\section{Experimental Results and Analysis}

5.1. The Influence of the Excitation Signals on the Guided Waves Detected by Piezoceramic Patches Attached to the Surface. Two piezoceramic patches were bonded on the surface of the concrete specimen, as shown in Figure 5. The smart aggregate acted as a transmitter while the piezoceramic patches mounted on the specimen surface were used as receivers. Then, guided waves (detected by the surface mounted piezoceramic patches) were measured. The recorded data are shown in Figure 6.

As can be seen in Figure 6, the value of PZT-S1 is bigger than that of PZT-S2, since PZT-S1 is placed closer to the smart aggregate. However, the two curves (for the two piezoceramic patches) show similar amplitude-frequency variations. The curves show three stages of variation. First, the amplitudes show an increasing trend; then the amplitudes remain almost unchanged or decrease slightly after reaching the maximum values for about the same duration; finally, the amplitudes 


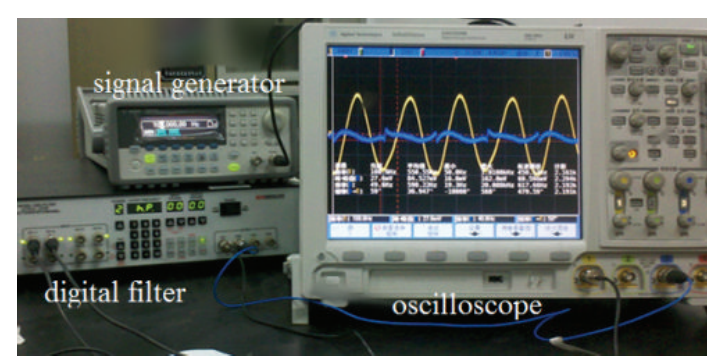

(a)

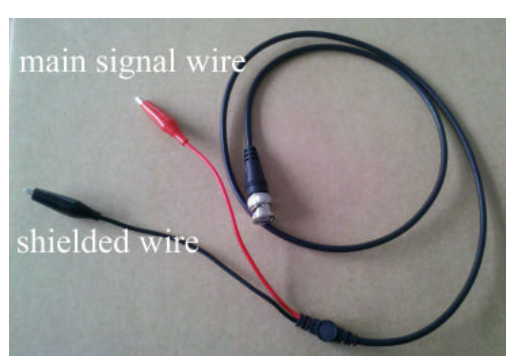

(b)

Figure 4: Devices and cables used in the experiment.

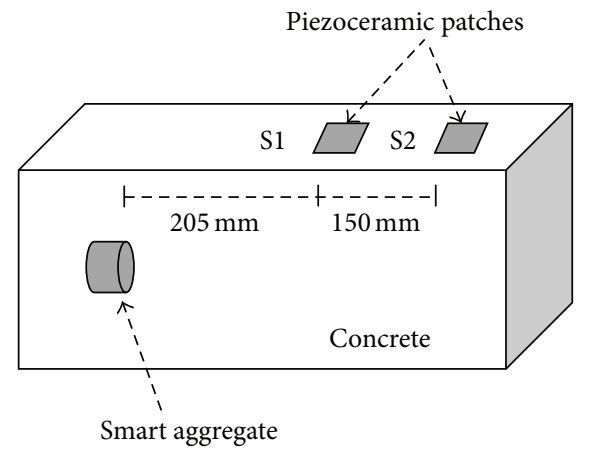

Figure 5: Locations of the smart aggregate and the piezoceramic patches on the specimen.

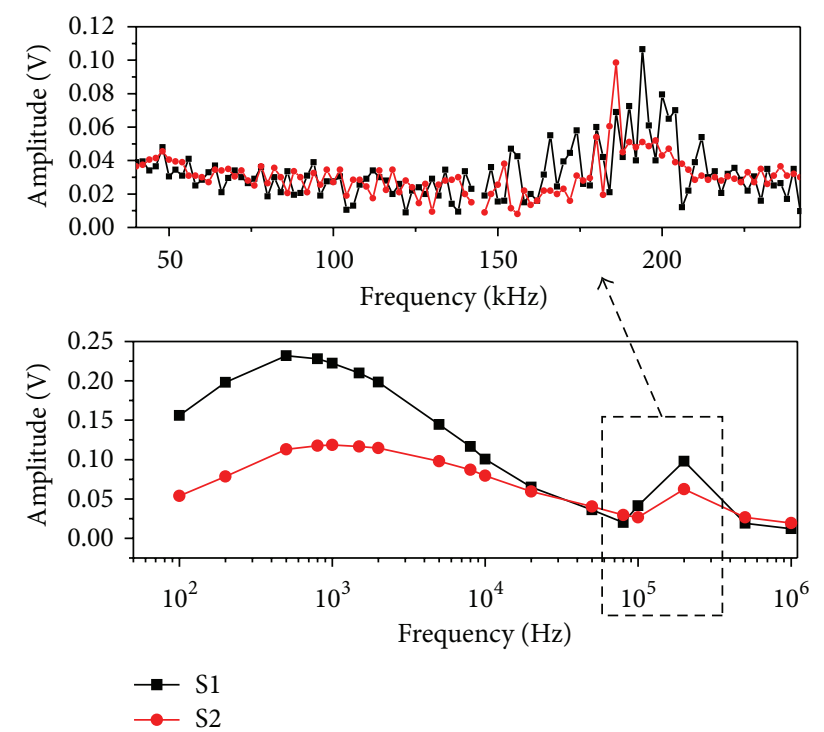

Figure 6: Relationships between the signal frequency and its amplitude recorded by the surface mounted piezoceramic patches.

show a decreasing trend before a noticeable amplitude fluctuation between $50 \mathrm{kHz}$ and $500 \mathrm{kHz}$ frequency range.

One possible explanation of these amplitude fluctuations is that they result from the resonance of the piezoceramic patches. It is well known that every structure has a natural resonance frequency which is determined by its material properties and geometrical shape. Therefore, when the frequency of the external excitation is equal to its natural frequency, resonance occurs. The resonance induces relatively larger vibration amplitudes, and as a result the quantity of electric charge on the surface of the piezoceramic patch increases due to the larger vibratory motion. It gives rise to large fluctuating peak in the signal recorded by the surface mounted piezoceramic patch when the external excitation frequency is near the resonance frequency.

To verify the resonance frequency postulate, the frequencies of the first ten modes of the piezoceramic patch were calculated using the finite element method. Some of these results are shown in Figure 7. The plots show the modal shapes in the form of contour plots of the out-of-plane displacement field amplitudes. The finite element program MacNeal-Schwendler Corporation (MSC) Marc is used for this computation. The finite element model is analysed with 16008 -node solid elements. In the finite element simulation, the problem geometry, the material properties, and the constraint conditions (the contact condition between the concrete and the piezoceramic patch) are assumed to be the same as those of the piezoceramic patch used in the experiment. The patch size is $10 \mathrm{~mm} \times 10 \mathrm{~mm} \times 1 \mathrm{~mm}$, its Young's modulus is $6.6 \times 1010 \mathrm{~N} / \mathrm{m}$, and its density is 7.5 $\times 103 \mathrm{~kg} / \mathrm{m}^{3}$. The finite element results showed that the frequencies of the first ten modes of the piezoceramic patch were between $10.07 \mathrm{kHz}$ and $198.90 \mathrm{kHz}$, which is close to the fluctuating frequency range in the experiment as shown in Figure 6.

5.2. The Effectiveness of the Combination of the Smart Aggregate and Piezoceramic Patches for SHM of Concrete Structures. Three-point bending test of the concrete beam was conducted with a loading rate of $1.2 \mathrm{~mm} / \mathrm{min}$ to study the effectiveness of the smart aggregate and piezoceramic patch combination in monitoring accumulated damage in concrete. The signal (wave) amplitudes received by a piezoceramic patch were recorded at four stages: healthy stage (no crack is visible); stage 1 of damage (when a visible crack appears); stage 2 of damage (the maximum crack opening reaches $2.5 \mathrm{~mm}$ ), and stage 3 of damage (the maximum crack opening reaches $4 \mathrm{~mm}$, severe damage). The results are shown in Figure 8.

It can be seen from Figure 8 that the signal amplitudes decrease with the increase of damage when the signal frequency is smaller than $200 \mathrm{kHz}$. However, when the 


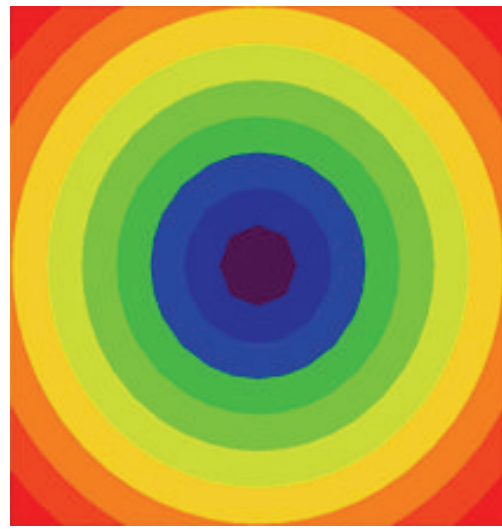

Mode 1: $10.07 \mathrm{kHz}$

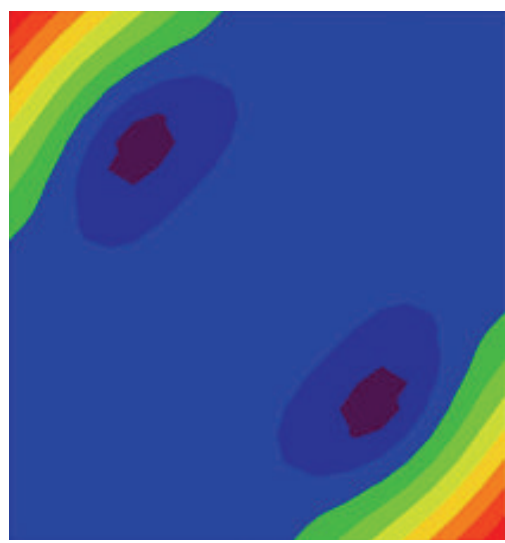

Mode 7: $145.73 \mathrm{kHz}$

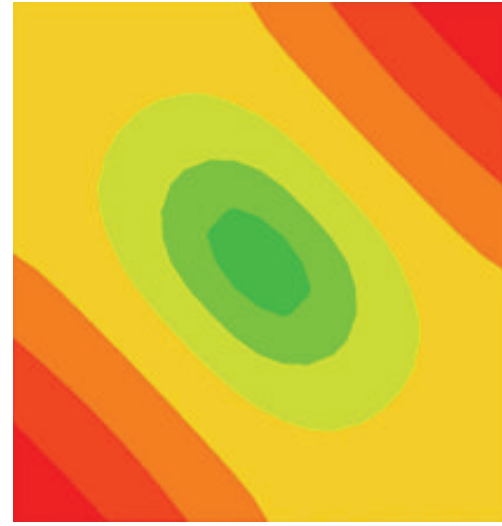

Mode 3: $55.30 \mathrm{kHz}$

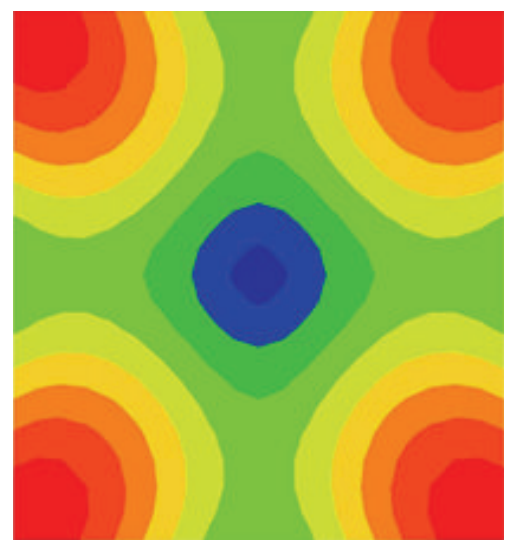

Mode 8: $185.79 \mathrm{kHz}$

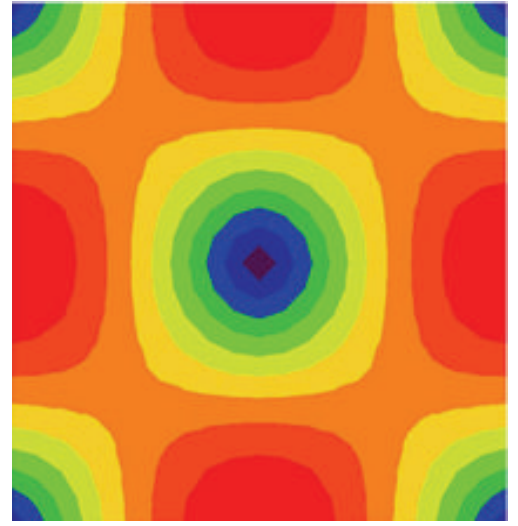

Mode 5: $140.86 \mathrm{kHz}$

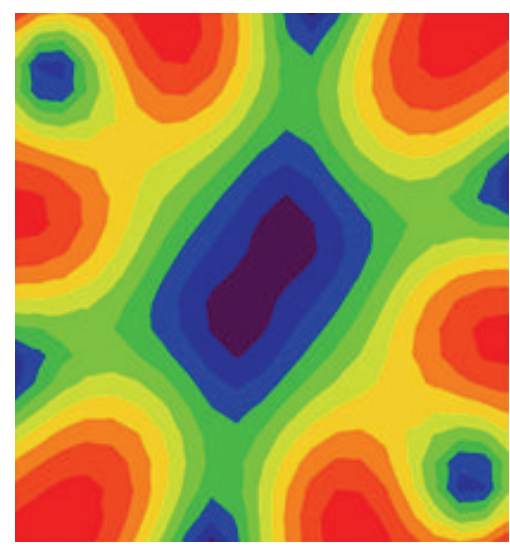

Mode 10: $198.90 \mathrm{kHz}$

FIgURE 7: Modal analysis results of the piezoceramic patch; contour plots show different mode shapes.

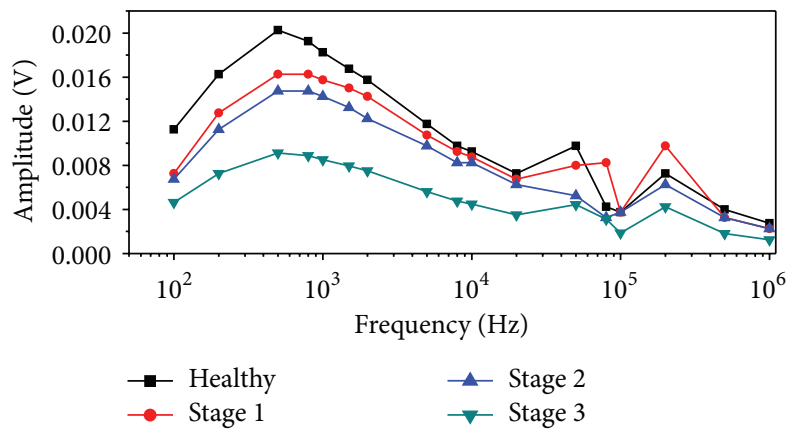

Figure 8: Amplitude-frequency variations recorded by surface mounted piezoceramic patches for different health states of the specimen.

signal frequency is greater than $200 \mathrm{kHz}$, there is a strong fluctuation in the signal amplitudes recorded by the piezoceramic patch. The reason for this fluctuation has been discussed in the above section. Therefore, it is important to select an appropriate frequency for damage detection in concrete structures avoiding the resonance frequencies of the piezoceramic patch geometries.

The proposed damage index was used to quantify the state of health of the concrete beam. The damage index values at different stages of damaged concrete are shown in Figure 9(a). Figure 9(b) shows the damaged concrete beam after testing. To avoid the strong fluctuation in the signal amplitudes above $20 \mathrm{kHz}$ frequency, only the amplitude results at lower frequencies were used for damage index calculation. It can be seen that the damage index increases significantly with increasing damage in the concrete beam. Therefore, the proposed method is feasible for evaluating and monitoring the health of concrete structures.

\section{Conclusion}

The embedded smart aggregate and surface mounted piezoceramic patch combination is used for monitoring damage in concrete beam structures. Sinusoidal signals with constant amplitudes and varying frequency $(100 \mathrm{~Hz}$ to $1 \mathrm{MHz})$ were used as the excitation signals. The smart aggregate acted as the transmitter generating the sinusoidal signals and piezoceramic patches were used as the receivers recording the elastic waves on the surface. The main conclusions from this experimental investigation are as follows:

(1) It is important to select the right frequency for damage detection in concrete structures by the proposed 


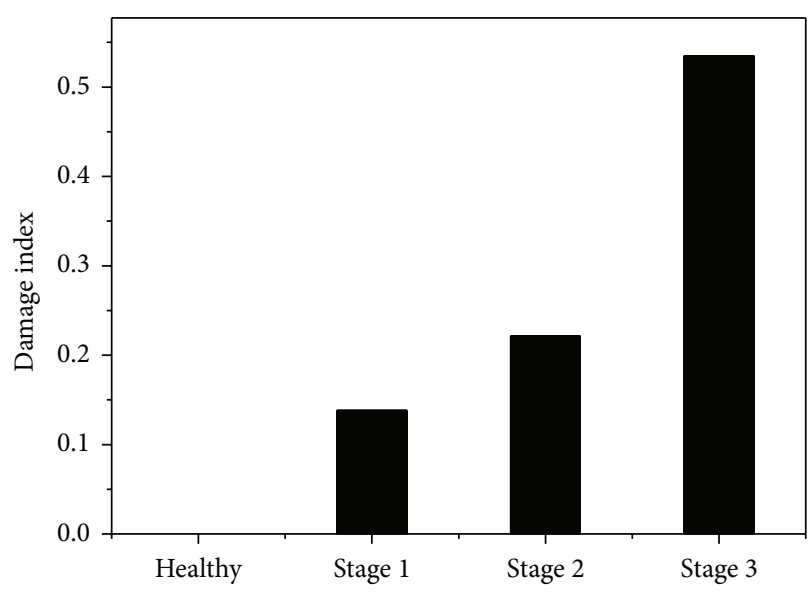

(a)

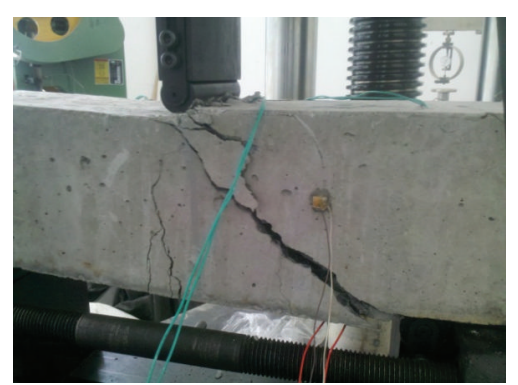

(b)

FIGURE 9: (a) Damage indices for healthy and damaged structures, (b) damaged beam after three-point bending experiment.

method. Amplitude fluctuations near the resonance frequency of the patch geometry should be avoided.

(2) The embedded smart aggregate and the surface mounted piezoceramic patch combination is an effective tool for monitoring health of concrete structures from the amplitudes of the recorded wave signals.

(3) A damage index expression is proposed that can clearly show the evolution of the damage in a quantitative manner.

The authors believe that this investigation will result in further development of the smart aggregate for embedment and piezoceramic patch geometries for surface mounting in concrete structure inspection.

\section{Conflict of Interests}

The authors declare that there is no conflict of interests regarding the publication of this paper.

\section{Acknowledgments}

This study was supported by the National Natural Science Foundation of China under Grants nos. 51579086, 51379068, and 51139001; Jiangsu Natural Science Foundation under Grant no. BK20140039; and Research Fund for the Doctoral Program of Higher Education of China under Grant no. 20120094110005.

\section{References}

[1] A. Raghavan and C. E. Cesnik, "Review of guided-wave structural health monitoring," Shock and Vibration Digest, vol. 39, pp. 91-116, 2007.

[2] W. Na, T. Kundu, and M. R. Ehsani, "Ultrasonic guided waves for steel bar concrete interface testing," ARIEL, vol. 129, pp. 31248, 2002.

[3] Y. Wang, X. Zhu, H. Hao, and J. Ou, "Guided wave propagation and spectral element method for debonding damage assessment in RC structures," Journal of Sound and Vibration, vol. 324, no. 3-5, pp. 751-772, 2009.

[4] T. H. Miller, T. Kundu, J. Huang, and J. Y. Grill, "A new guided wave-based technique for corrosion monitoring in reinforced concrete," Structural Health Monitoring, vol. 12, no. 1, pp. 35-47, 2013.

[5] J. L. Rose, "A baseline and vision of ultrasonic guided wave inspection potential," Journal of Pressure Vessel Technology, vol. 124, no. 3, pp. 273-282, 2002.

[6] J. L. Rose, "Guided wave nuances for ultrasonic nondestructive evaluation," IEEE Transactions on Ultrasonics, Ferroelectrics, and Frequency Control, vol. 47, no. 3, pp. 575-583, 2000.

[7] W.-B. Na, T. Kundu, and Y.-S. Ryu, "Underwater inspection of concrete-filled steel pipes using guided waves," KSCE Journal of Civil Engineering, vol. 6, no. 1, pp. 25-31, 2002.

[8] W.-B. Na, T. Kundu, and M. R. Ehsani, "A comparison of steel/ concrete and glass fiber reinforced polymers/concrete interface testing by guided waves," Materials Evaluation, vol. 61, no. 2, pp. 155-161, 2003.

[9] F. Lanza di Scalea, P. Rizzo, and F. Seible, "Stress measurement and defect detection in steel strands by guided stress waves," Journal of Materials in Civil Engineering, vol. 15, no. 3, pp. 219227, 2003.

[10] T. Kundu, S. Banerjee, and K. V. Jata, "An experimental investigation of guided wave propagation in corrugated plates showing stop bands and pass bands," The Journal of the Acoustical Society of America, vol. 120, no. 3, pp. 1217-1226, 2006.

[11] R. Ahmad, S. Banerjee, and T. Kundu, "Pipe wall damage detection in buried pipes using guided waves," Journal of Pressure Vessel Technology, vol. 131, no. 1, Article ID 011501, 2009.

[12] G. Song, H. Gu, Y. L. Mo, T. T. C. Hsu, and H. Dhonde, "Concrete structural health monitoring using embedded piezoceramic transducers," Smart Materials and Structures, vol. 16, no. 4, pp. 959-968, 2007.

[13] G. Song, H. Gu, and Y.-L. Mo, "Smart aggregates: multifunctional sensors for concrete structures-a tutorial and a review," Smart Materials and Structures, vol. 17, no. 3, Article ID 033001, 2008.

[14] H. Gu, Y. Moslehy, D. Sanders, G. Song, and Y. L. Mo, "Multifunctional smart aggregate-based structural health monitoring 
of circular reinforced concrete columns subjected to seismic excitations," Smart Materials and Structures, vol. 19, no. 6, Article ID 065026, 2010.

[15] W.-I. Liao, J. X. Wang, G. Song et al., "Structural health monitoring of concrete columns subjected to seismic excitations using piezoceramic-based sensors," Smart Materials and Structures, vol. 20, no. 12, Article ID 125015, 2011. 


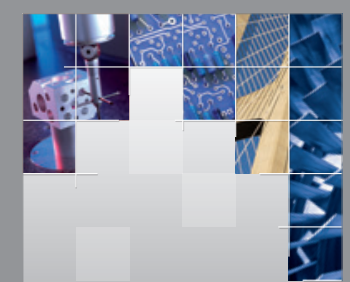

\section{Enfincering}
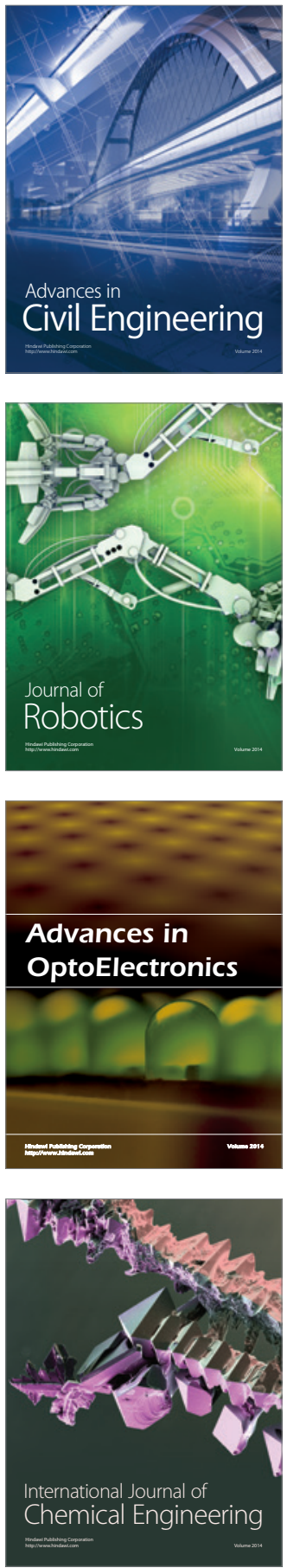

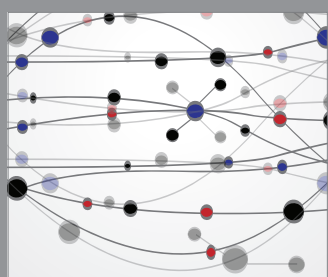

The Scientific World Journal

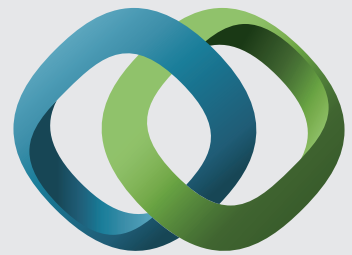

\section{Hindawi}

Submit your manuscripts at

http://www.hindawi.com
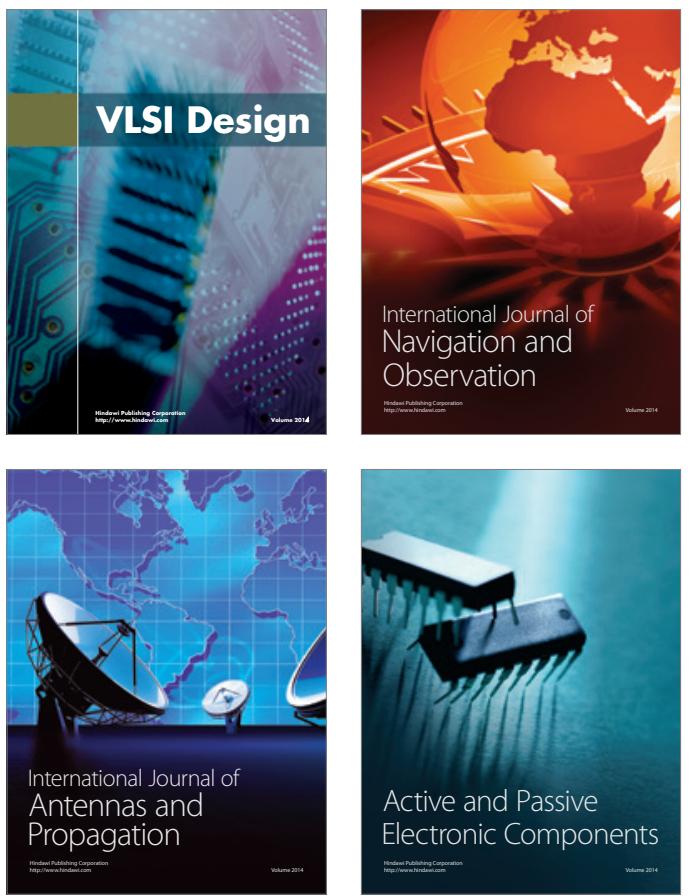
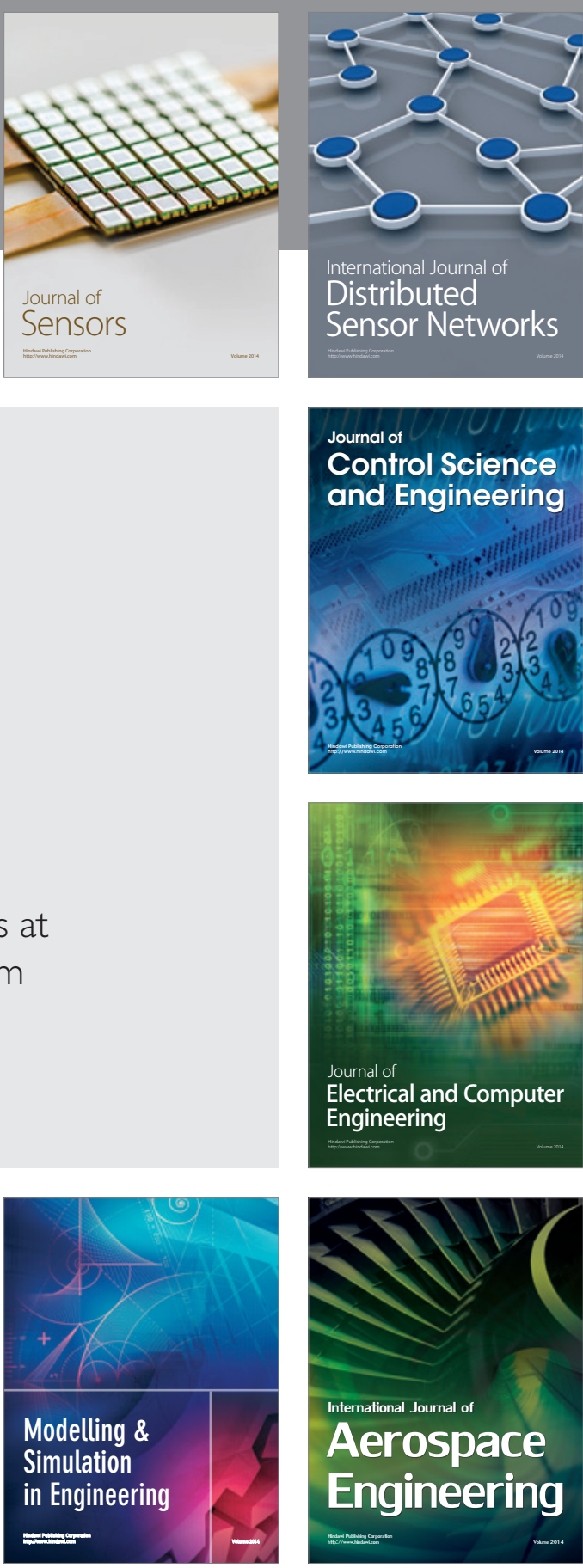

International Journal of

Distributed

Sensor Networks

Journal of

Control Science

and Engineering
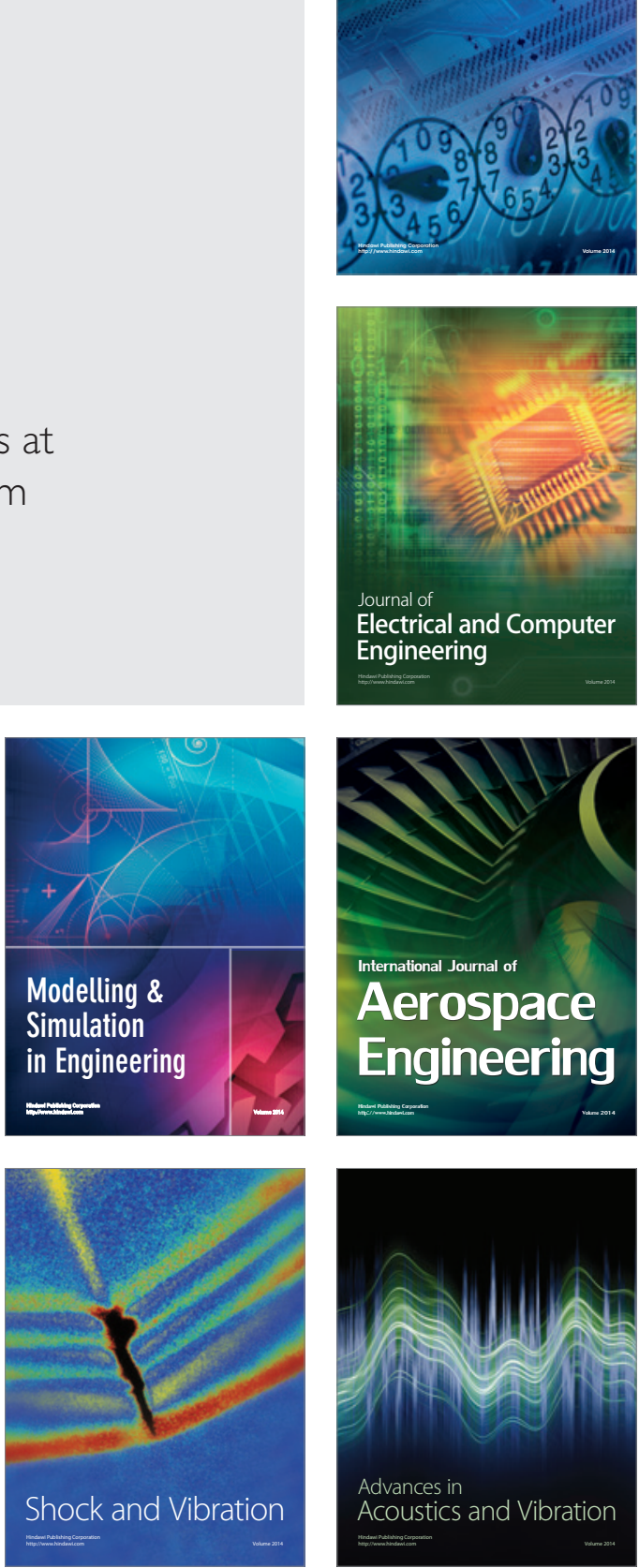